Article

\title{
Analysis of Cold Dwell Fatigue Crack Initiation Site in a $\beta$-Forged Ti-6242 Disk in Relation with Local Texture
}

\author{
Lionel Germain ${ }^{1,2, * \mathbb{C}}$, Youssef Samih ${ }^{1}$, Pierre Delaleau ${ }^{3}$, Joseph Gilgert ${ }^{1}$ and Nathalie Gey ${ }^{1,2}$ \\ 1 LEM3, Université de Lorraine, CNRS, Arts et Métiers ParisTech, F-57000 Metz, France; \\ youssef.samih@synergie4.com (Y.S.); joseph.gilgert@univ-lorraine.fr (J.G.); \\ nathalie.gey@univ-lorraine.fr (N.G.) \\ 2 DAMAS, Laboratory of Excellence on Design of Alloy Metals for Low-Mass Structures, \\ Université de Lorraine, F-57000 Metz, France \\ 3 SAFRAN Aircraft Engines, Site de Gennevilliers, 92700 Colombes, France; pierre.delaleau@safrangroup.com \\ * Correspondence: lionel.germain@univ-lorraine.fr; Tel.: +33-372-747-800
}

Received: 17 June 2020; Accepted: 8 July 2020; Published: 15 July 2020

\begin{abstract}
The $\alpha$ and prior $\beta$ textures and microtextures of a lamellar Ti6242 forged disk were characterized by advanced electron back scattered diffraction (EBSD) and related to crystallographic features of faceted crack initiation sites of dwell fatigue specimens tested along the radial direction (RD). Large feather-like structures of $\alpha$ colonies with close orientations were observed at boundaries of elongated prior $\beta$ grains. Their orientation belongs to the $<11-20>\alpha / / z$ fiber, aligning the $c$-axis in RDs (z: axial direction of the disk). They are inherited from prior $\beta$ grains belonging to the major $<100>\beta$ and minor $<111>\beta / / z$ fibers. These feather-like structures are strong regions of the forging that act as a preferential crack initiation site. Adjacent to them, one can observe large colony with evidence of prismatic slip. Thus, the facet formation seems triggered by stress redistribution from "weak" to "strong" regions due to the elastic and plastic anisotropy. Finally, the occurrence of neighboring $\beta$ grains able to share close oriented feather-like colonies is discussed considering the reconstructed $\beta$ microtexture and texture. This study may be helpful for further texture control during the forging process.
\end{abstract}

Keywords: fatigue; fractography; titanium alloys; bimodal microstructure; EBSD

\section{Introduction}

The application of near $\alpha$ titanium alloys in critical application may be limited by their sensitivity to dwell fatigue. Under certain conditions of stress and temperature, dwell sensitivity reduces the fatigue life by a decade when submitted to a trapezoidal waveform (load maintained at peak stress) compared with a classical triangular or sinusoidal waveforms [1-3]. This phenomenon is well documented for bimodal microstructures [4-6] where crack initiation is dominated by the developments of quasi-cleavage facets along the basal plane in the $\alpha_{p}$ nodules [7]. In lamellar, facets form in Widmanstätten colonies either in a single colony or adjacent colonies sharing the same c-axis [8].

Among the mechanisms explaining facet formation, the Stroh model is often cited and serves as a basis for more complex models [9-11]. In the Stroh model, a 'hard' grain (i.e., with its c-axis close to the applied load) is adjacent with a 'soft' grain. Plasticity in the soft grains accumulate dislocations in the vicinity of the hard grain, inducing a shear stress which leads to cleavage under the macroscopic applied load. This mechanism suggests that the texture and microtexture should play a role in the occurrence of facet formation, but unfortunately this role was little studied in the literature on lamellar microstructures. 
Several investigations focused on the microstructural effect on the dwell sensitivity. They showed the crack growth in colony structure is slower than in elongated and equiaxed structure [12,13]. Lefranc found also that micro voids formed by coalescence of cavities nucleated at $\alpha / \beta$ interfaces along localized slip bands in aligned colonies of $\alpha$ laths [14]. However, several questions remain open concerning lamellar microstructures, i.e., which microtexture are dwell sensitive? How do they form? Is there a way to optimize the processing route to limit their occurrence?

Therefore, the aim of this contribution is to characterize the $\alpha$ and prior $\beta$ microstructure and microtexture behind faceted crack initiation sites in lamellar titanium Ti-6242 disk. The origin of those weak points of the microstructure and new insights for further forging process optimization are discussed.

\section{Materials and Methods}

\subsection{Material and Fatigue Testing}

A Ti-6242 compressor disk was supplied by Safran Aircraft Engines (Figure 1a). For mechanical properties of this alloy, the reader can refer to the Phd thesis of Thungen [15]. It was forged in the $\beta$ domain and further annealed in the $\alpha / \beta$ domain. Its resulting microstructure is mainly made of pancaked prior $\beta$ grains with a thickness of $\sim 80 \mu \mathrm{m}$ and a radius of few millimeters (Figure 1b). Those $\beta$ grains transformed into $\alpha$ lamellae (2-3 $\mu \mathrm{m}$ thick) during cooling, wetting first the $\beta$ boundaries (called $\left.\alpha_{\mathrm{GB}}\right)$ before emitting lamellar Widmanstätten colonies (Figure 1c). At some locations, these colonies expand at each side of the boundary, forming a feather-like structure. They can reach a length of several hundred of $\mu \mathrm{m}$ along the $\beta$ grain boundary and develop inside the grain over 50 to $150 \mu \mathrm{m}$. In the core of the $\beta$ grains, the $\alpha$ phase was mostly arranged in basket weave (Figure $1 \mathrm{~d}$ ). During annealing, $\alpha$ needles are formed in the residual $\beta$ phase (only visible at higher magnification in Figure 1d).

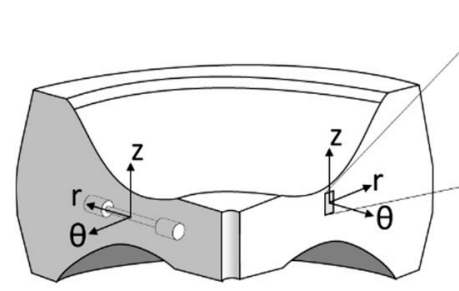

(a)

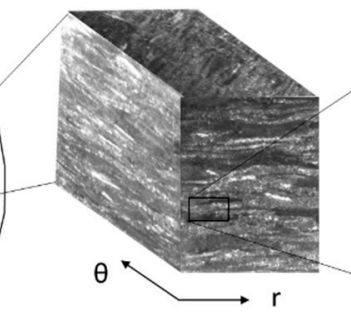

(b)

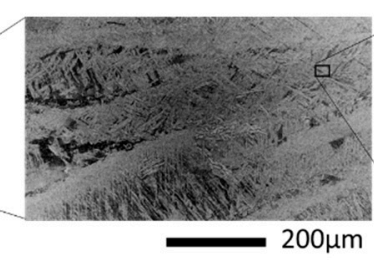

(c)

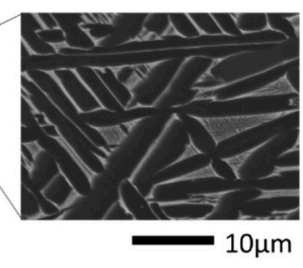

(d)

Figure 1. (a) Schematic of the forged disk with the reference frame used in this study and the region of interest for microstructure characterization and fatigue tests; (b) Macrography of the microstructure in 3 orthogonal directions (c) $\alpha$ lamellae structure formed in millimeter large and elongated prior $\beta$ grains, (d) residual $\beta$-phase layers (in white) and $\alpha$ needles formed during aging in the $\alpha / \beta$ field.

Different fatigue specimens were cut radially from the disk, in the most deformed region during $\beta$-forging (Figure 1a). The smooth dog-bone shaped specimens had a gage diameter of $6.3 \mathrm{~mm}$ and a gage length of $30 \mathrm{~mm}$. Dwell fatigue tests were conducted to failure under the following conditions: trapezoidal wave form loading with an applied stress of $900 \mathrm{MPa}, \mathrm{R}=0$, a dwell period of $120 \mathrm{~s}$, and a load/unload period of $1.5 \mathrm{~s}$. The number of cycles to failure was 3219 and 3877 and similar fracture surfaces were observed.

\subsection{Microstructure and Local Texture Analysis of the Forged Disk and Fractured Specimen}

Scanning electron microscopes (SEMs) Jeol JSM-6490 and Jeol JSM-6500F (Tokyo, Japan) equipped with EBSD systems Nordlys S Camera from Oxford instruments (Abingdon, UK) were used for microstructure and local texture analysis. The microstructure was revealed using Kroll's (Solution 
of $4 \% \mathrm{HNO}_{3}+2 \% \mathrm{HF}$ ) reagent after polishing up to a 4000 -grid silicon paper. EBSD measurements required an extra final polishing step with a mixture of colloidal silica solution (OP-S- $0.25 \mu \mathrm{m})$ and hydrogen peroxide.

Large areas of the most deformed region of the disk were scanned by EBSD with a step size of $5 \mu \mathrm{m}$ by combined beam and stage movements. Due to this large step size compared to the thickness of $\alpha p$ lamellae $(2-3 \mu \mathrm{m})$, the fraction of non-indexed points increased to $40 \%$ in the basket weave domains. The missing data were extrapolated with the closest neighbor approximation within a distance of two pixels maximum. Additional EBSD maps were acquired with reduced step sizes of 1.5, 0.7 , and $0.5 \mu \mathrm{m}$ to better characterize the local texture in relation with the microstructure. EBSD maps are mostly plotted as inverse pole figure (IPF) maps either with respect to the forging direction $\mathrm{z}$ or with respect to the radial direction $r$ of the fatigue specimens.

The crack initiation sites of the fractured specimens were characterized by SEM and EBSD. For one sample, two orthogonal sections were analyzed: parallel and perpendicular to the main crack initiation site. First, successive polishing steps over the fracture surface were performed on one part to identify the microstructure/microtexture underneath a crack nucleation site. Then, an additional transverse cut was performed on the other part to analyze the tri-dimensional neighborhood of the same site.

Finally, our homemade reconstruction software (Merengue2) was applied to identify the prior $\beta$ grain shapes and orientations on the inherited $\alpha$ map [16,17]. It uses the Burgers orientation relation (BOR) between both phases:

$$
\begin{aligned}
& (110)_{\beta} / /(0001)_{\alpha} \\
& {[\overline{1} 1 \overline{1}]_{\beta} / /[2 \overline{1} \overline{1} 0]_{\alpha}} \\
& (\overline{1} 12)_{\beta} / /(0110)_{\alpha}
\end{aligned}
$$

According to it, 12 crystallographic $\alpha$ orientations called variants are related to a single $\beta$ orientation. The method finds the most likely $\beta$ orientation related to a set of neighboring $\alpha$ orientations [18]. For the present study, the version of the algorithm dedicated to 'deformed parent microstructure' was used to account for the orientation gradient in the parent phase prior to transformation [19].

In addition, the $\alpha$ and $\beta$ EBSD maps acquired over the forged disk were processed with DECRYPT (Direct Evaluation of CRYstallographic Phase Transformation, LEM3, Metz, France), our home-made software dedicated to analyzing the orientation data inherited by OR-based phase transformations [20]. First, it was applied on the reconstructed $\beta$ map to quantify the fraction of specific prior $\beta$ GBs able to share close-oriented $\alpha$ colonies. This ability requires that the $\beta$ GBs belong to one of the special boundaries listed in Table 1 [20]. Second, the tendency of these specific $\beta$ GBs to promote these close-oriented colonies at each side of the GB was quantify on the corresponding $\alpha$ map.

Table 1. Special disorientations for which two $\beta$ grains share common variants (the number of common variants is also indicated).

\begin{tabular}{ccc}
\hline Special $\beta$ GB Type & $\beta / \beta$ Disorientation & Common Variants \\
\hline I & $10.5^{\circ}<110>$ & 1 \\
II & $49.5^{\circ}<110>$ & 1 \\
III & $60^{\circ}<110>$ & 2 \\
IV & $60^{\circ}<111>$ & 3 \\
\hline
\end{tabular}

\section{Results}

\subsection{Microstructure and Microtexture of the Most Deformed Region of the Ti-6242 Disk}

Figure 2a,b gives a large $\alpha$ EBSD map acquired in the $(\theta, z)$ plane of the disk and the corresponding pole figures with the forging direction $\mathrm{z}$ in the center. The $\alpha$ texture is sharp in this region subjected to high level of deformation by forging. More than $30 \%$ of the $\alpha$ lamellae belong to the main fiber-texture 
component referenced $<11-20>\alpha / / z$. They align the a-direction of the hexagonal lattice $(<11-20>)$ with the forging direction $\mathrm{z}$ and have the c-axis randomly distributed perpendicularly to $\mathrm{z}$ (Figure $2 \mathrm{~b}$ ).
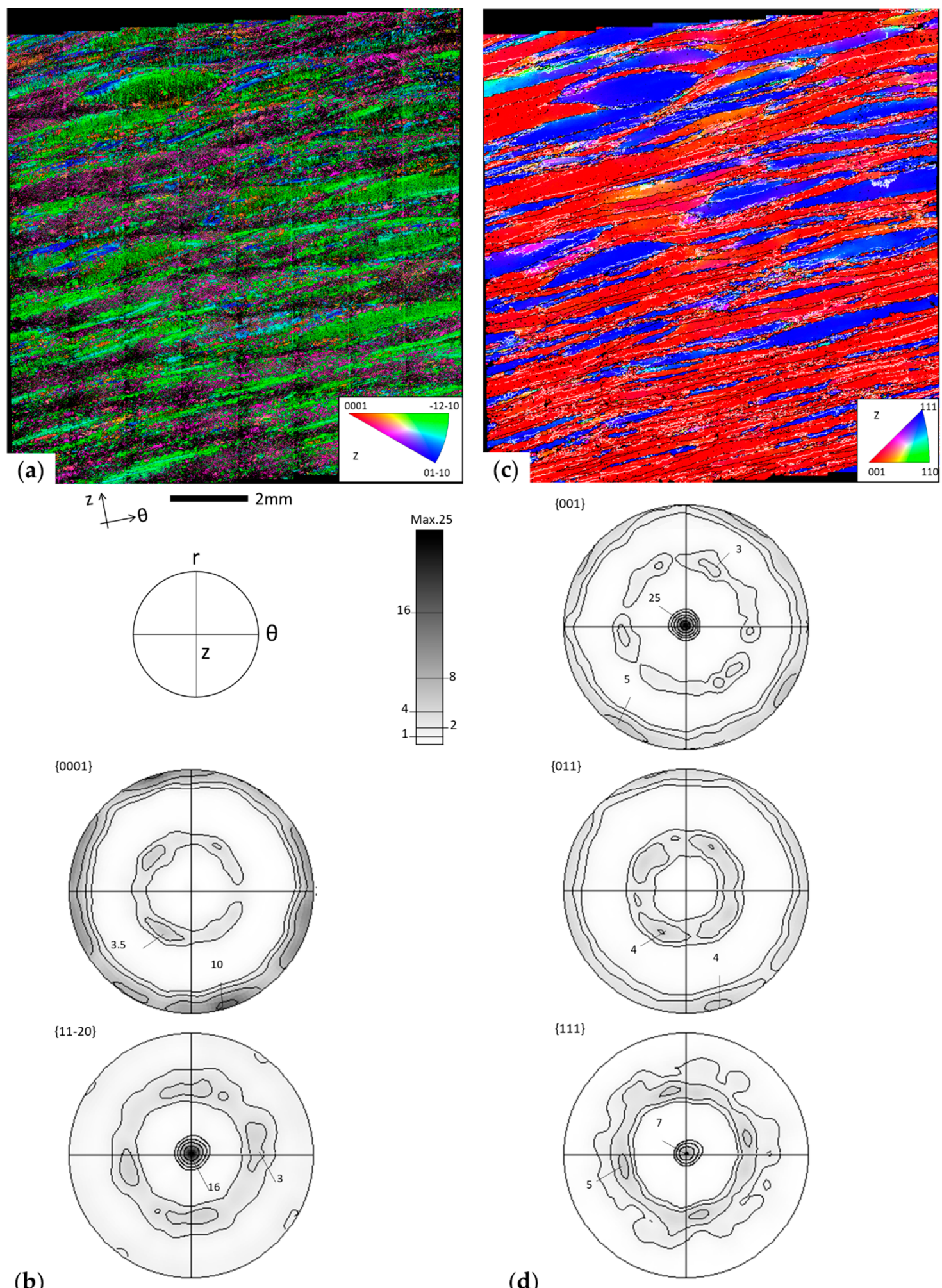

(b)

(d)

Figure 2. Microtexture and Texture of the disk: maps (a) IPF//Z EBSD map of the measured $\alpha$ phase; (b) Corresponding texture; (c) IPF//Z EBSD map of the reconstructed $\beta$ phase (High Angle misorientations $>15^{\circ}$ are plotted in black and Low Angle misorientations in white); (d) Corresponding texture. 
The $\alpha$ lamellae belonging to this main $<11-20>\alpha / / z$ fiber component are colored in green in the EBSD map according to the IPF//z color key (Figure 2a). They are organized in large Widmanstätten colonies forming close-oriented domains with a length ranging from 500 to $3000 \mu \mathrm{m}$ (the peak in the distribution is around $900 \mu \mathrm{m})$. They reveal the elongated shape of the prior $\beta$ grains. Inside each domain, a large and continuous orientation spread is observed. This indicates a progressive misorientation from one lamella to the next, mostly inherited from the orientation gradient in the prior $\beta$ phase induced during the forging step.

Finally, a minor $\alpha$ fiber component is also observed with c-axes at $45-56^{\circ}$ from $\mathrm{z}$. In the EBSD map, it is displayed in orange/pink and correspond mostly to $\alpha$ lamellae organized in basket-weaves. Actually, it is two close $\alpha$ fibers with components corresponding approximately to a $\{40-47\} \perp \mathrm{z}$ (pink) and a $\{2-429\} \perp z$ (orange). They represent $11 \%$ of the volume fraction. Even if the indexing rate was reduced in these regions, it was possible to evaluate that they form close-oriented domains with a size below $200 \mu \mathrm{m}$ in most of cases (peak at $60 \mu \mathrm{m}$ ).

To analyze the origin of the sharp $\alpha$ texture and microtexture, the prior $\beta$ orientation map has been reconstructed from the measured $\alpha$ one. Figure $2 c, d$ displays the resulting $\beta-I P F / / z$ map with high and low angle boundaries (HAGB/LAGB), plotted respectively in black and white and the corresponding $\beta$ pole figures with the forging direction $\mathrm{z}$ in the center.

The prior $\beta$-forged texture is also very sharp and characterized by two fibers: $54 \%$ of $<100>/ / \mathrm{z}$ ( $\beta$ grains in red in the EBSD map often separated by HAGBs) and $26 \%$ of $<111>/ / z$ ( $\beta$ grains in blue in the EBSD map). These two fibers develop classically in bcc materials after uniaxial compression [21-24].

As seen in the reconstructed $\beta$ map, the $\beta$ grains are elongated in the $\theta$ direction and their length scales in the millimeter range. Some small grains are decorating the boundaries; they are inherited from recrystallization [25]. The aspect ratio of the $\beta$ elongated grains seems to depend on their texture component; the $<111>\beta / / \mathrm{z}$ grains are significantly larger with a smaller aspect ratio than the $<100>\beta / / \mathrm{z}$ grains. Also, the orientation gradient inside the $\beta$ grains have been evaluated by calculating for each $\beta$ grains the average deviation of each pixel with the mean grain orientation (parameter called GOS [26]). $\beta$ grains with the highest GOS values seems to belong to the $<100>/ / z$ fiber. Those results suggest an orientation dependence to internal stored energy as already observed in BCC transition metals [27].

The large $\alpha$ feather-like structure develops from specific $\beta$ GBs able to share close $\alpha$ orientations (see Table 1 ) as observed by comparing the measured $\alpha$ and the reconstructed $\beta$ maps. These boundaries separate $\beta$ grains belonging either to the same $<100>\beta / / z$ fiber (mostly LAGBs) or respectively to $<100>\beta$ and $<111>\beta / / z$ fibers (HAGBs). The thickest $\alpha$ domains are detected in this latter case due to the larger width of the $<111>\beta / / \mathrm{z}$ grains.

Large $\alpha$ feather-like structures extending over three prior $\beta$ grains can even be observed in the material (the $\beta$ grain in the middle of the configuration being almost transformed to the unique common $\alpha$ orientation between the three $\beta$ grains). This is further illustrated in Figure 3 with an EBSD map acquired with a step size of $1.5 \mu \mathrm{m}$. Close to the center of the $\alpha$ map (Figure 3c), three $\alpha$ colonies separated by LAGBs are clearly seen. The close-up view Figure $3 \mathrm{~d}$ includes the overlap of the Kikuchi Pattern Quality map and reveals the morphological orientations of the $\alpha$ lamellae in each colony (see the black dashed lines). They develop over the $<111>/ / z$ blue $\beta$ grain in sandwich between two $<100>/ / z \beta$ grains (see Figure 3a). These $\beta$ grains are disoriented close to $49.5^{\circ}<110>$. Consequently, they share a common $\{110\}$ plane and have two $<111>$ directions at $60^{\circ}$ from each other (they are encircled in the corresponding $\beta$-PFs). This misorientation allows the three $\beta$-grains to share a common $\alpha$ orientation that is preferentially selected to form the extended $\alpha$ domain (this $\alpha$ orientation is plotted in the corresponding $\alpha-\mathrm{PFs}$ ). It can be noted that such configurations are complex to reconstruct. In this example, only two pieces of information confirmed the existence of the sandwiched $<111>\beta$ grain: (1) The presence of a small orange lamella in BOR with the $<111>$ grain only (in the top middle of Figure $3 \mathrm{~d}$ ) and (2) a closer look at the lamellar microstructure which revealed that the colonies were separated by a discontinuous $\alpha_{G B}$ layer. The occurrence frequency of such a situation in the material requires analysis by EBSD large fields with a small step size. 


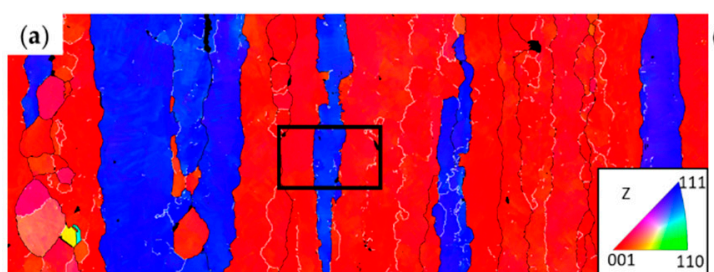
(c)

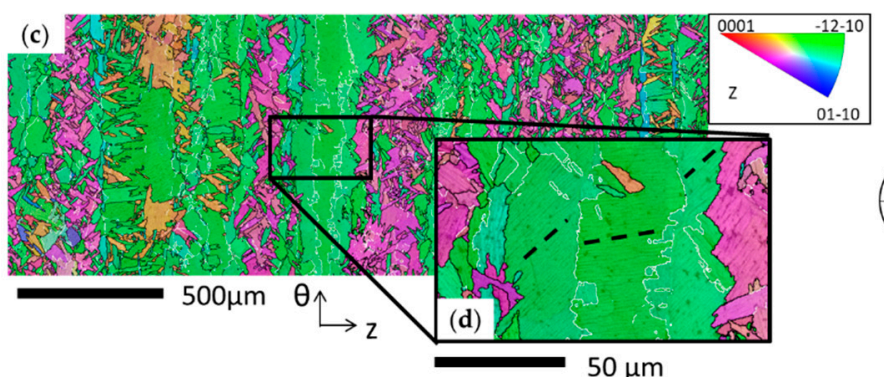

$50 \mu \mathrm{m}$

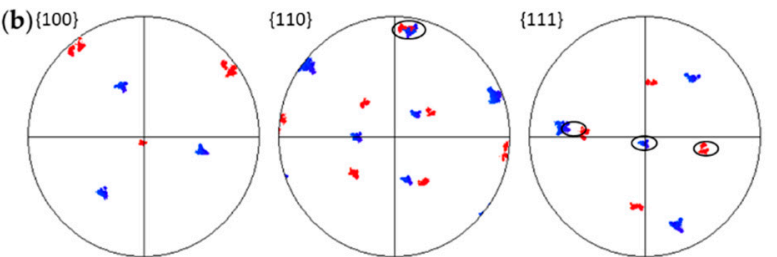

(e)
$\{0001\}$

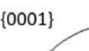

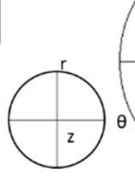

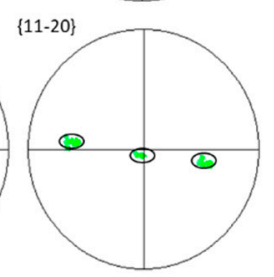

Figure 3. Local microtexture in the disk: (a) IPF//z EBSD maps for the reconstructed $\beta$ phase and (b) orientations of the three $\beta$ parents of the feather microstructure as PFs ( $\mathrm{z}$ in the center) (c) IPF//z EBSD maps for the measured $\alpha$ phase; (d) Close-up view of the three extended colonies, the overlap of the Kikuchi Pattern Quality map reveals the morphological orientations of the colonies (underlined with the black dashed lines); (e) $\alpha$ orientations of the feather-like colonies.

\subsection{Fractographic Features in Relation with the Microtexture}

The radial dwell fatigue specimens showed a rough and very uneven fracture surface. Several elongated facets, slightly tilted from the fractured plane and surrounded by micro-cracks were observed. Figure 4 displays SEM images of a typical fracture surface with multiple elongated facets. Figure $4 \mathrm{~b}$ is a zoom of the large facet (1.438 $\mathrm{mm}$ long) that is analyzed deeper in the following. The fracture surface also presents regions with micro-voids as boxed with a dashed line.

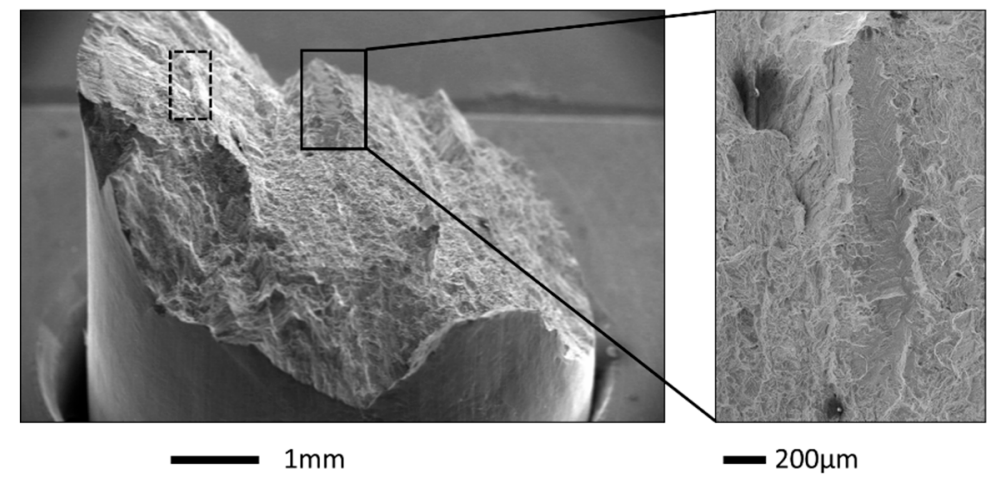

(a)

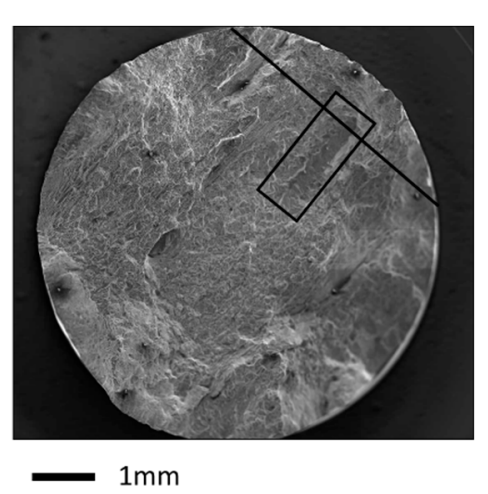

(c)

Figure 4. Fracture surface after dwell fatigue test along the radial direction $r$ : (a) Uneven surface from a tilted angle; (b) Zoom of the elongated facet; (c) Top view of the fracture surface The region boxed in black locate the zone polished for microstructure analysis; the line illustrates the cut for transverse microstructure analysis on the complementary section.

The microstructure underlying the zoomed facet in Figure $4 \mathrm{~b}$ is observed after a slight polishing in Figure 5. The backscattered image reveals that the facet covers two large $\alpha$ colonies growing at a prior $\beta$ boundary, itself decorated by a discontinuous $\alpha_{\mathrm{GB}}$ layer. 


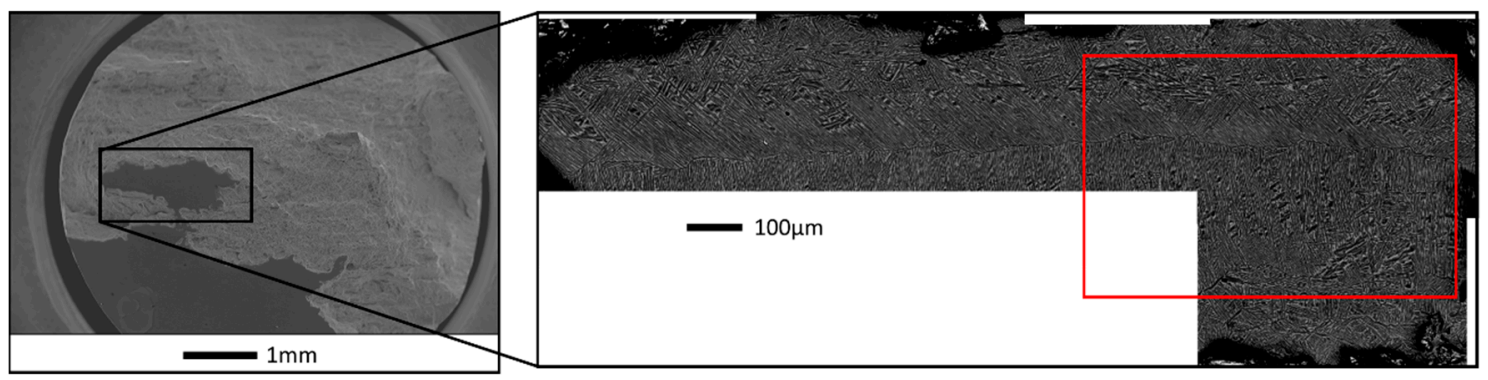

(a)

(b)

Figure 5. Fracture surface given in Figure 4 after polishing. (a) Macroscopic view; (b) Microstructure below the elongated facet seen Figure $4 \mathrm{~b}$, imaged with the BSE detector. The zone further analyzed by EBSD is boxed in red.

These $\alpha$ colonies share close orientations that belong to the main $\alpha$ fiber $<11-20>/ / z$ observed in the disk (shown in green Figure 2a). This is clearly seen on the $\alpha$-IPF//z map in Figure 6a performed over the zone boxed in red in Figure $5 b$. It was acquired with a step size of $0.5 \mu \mathrm{m}$ and covered $627 \times 442 \mu \mathrm{m}^{2}$. A $6-7^{\circ}$ low angle boundary separates both colonies (as revealed by the white misorientation line Figure 6a).

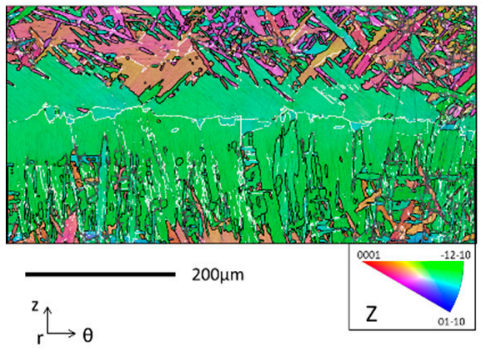

(a)
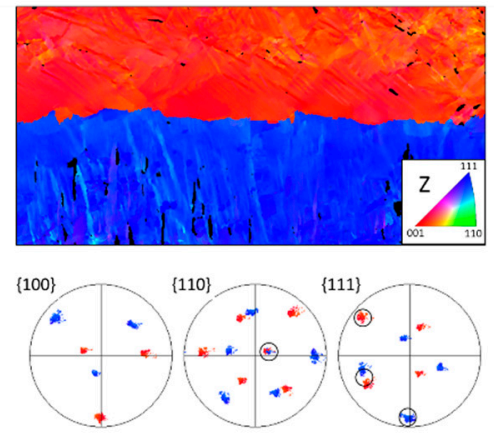

(b)

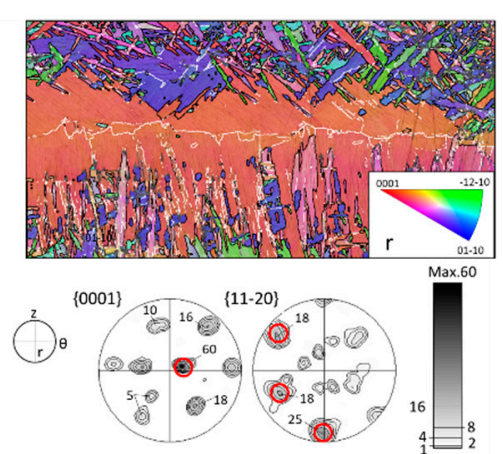

(c)

Figure 6. EBSD map acquired below the facet: (a) measured $\alpha \mathrm{IPF} / / \mathrm{z}$ map (angular misorientations between $3-15^{\circ}$ : in white); (b) reconstructed $\beta-\mathrm{IPF} / / \mathrm{z}$ map and discrete PFs of $\beta$ orientations close to the boundary; (c) measured $\alpha-\mathrm{IPF} / / \mathrm{r}$ map (angular misorientations between $3-15^{\circ}$ : in white) and corresponding $\alpha$ PF densities. The $\beta / \alpha$ poles implicated in the GB variant selection according to BOR are encircled on the corresponding PFs.

The reconstructed $\beta$-map $(\beta-\mathrm{IPF} / / \mathrm{z}$ in Figure $6 \mathrm{~b})$ indicates that these colonies are inherited from two differently oriented $\beta$ grains belonging to the $<100>/ / z$ (in red) and $<111>/ / z$ (in blue) fibers. These $\alpha$ colonies below the facet have the orientation of the closest variants between both prior $\beta$ grains as revealed by the comparison of the $\{110\} /\{111\} \beta$ PFs (Figure 6b) with the $\{0002\} /\{11-20\} \alpha$ PFs (Figure 6c). Notice that in this section, the center of the PFs is the radial direction $r$ corresponding to the tensile direction. The $\beta$ grains are disoriented by $\sim 53^{\circ}<110>$ (within $\pm 5^{\circ}$ scatter). This specific misorientation allows them to share a common $\{110\}$ pole and to have two $<111>$ at $\sim 60^{\circ}$, encircled on the $\beta$-PFs in Figure $6 \mathrm{~b}$. This defines the orientation of the feather like $\alpha$ colonies selected at the $\beta / \beta$ boundary, encircled on the $\alpha$-PFs in Figure $6 \mathrm{c}$. The c-axis of the colonies is at $18-22^{\circ}$ from the radial/tensile direction $r$ and is thus colored in red in the $\alpha-\mathrm{IPF} / / \mathrm{r}$ (Figure $6 \mathrm{c}$ ).

Finally, the comparison between the (0001) $\alpha$ and the $(110) \beta$ PFs reveals also that in the basket-weave region (nearby the colonies), most of the variants are present. The variant selection is definitely limited 
to the GB Widmanstätten precipitation. A similar analysis has been performed on the highly tilted region of the fracture surface mainly made of micro-voids (see the dotted box Figure 4). At this location, the lamellae were mostly arranged in basket-weaves, with different crystallographic orientations from one set of lamellae to the next. This arrangement is known to be more resistant to crack propagation and produced an uneven aspect of the fracture surface [28].

\subsection{Analysis of the Facet's Neighborhood}

The second part of the fractured specimen was polished perpendicularly to the fractured surface up to the facet to observe the 3D neighborhood of the feather-like colonies (full line Figure 4c illustrates the cutting plane). Figure 7 shows an analysis of EBSD data acquired in the $(\mathrm{z}, \mathrm{r})$ section. On the $\alpha$-IPF//r map (Figure 7a), the feather-like colonies below the facet are still colored in red. Interestingly, they are adjacent to a large colony (in blue in Figure 7a) that has undergone prismatic slip during the fatigue test. Indeed, the blue colony contains evidence of shear deformation that preceded the facet formation. Traces of slip bands are easily observed on the lath structure because of the sheared $\alpha / \beta$ lath interfaces. This shearing is seen in the EBSD map (in the white ellipse in Figure 7a). Indeed, the sheared lines exhibit low Kikuchi pattern quality and consequently a low indexing rate at this location. It is also confirmed on the high magnification BSE micrograph Figure 8.
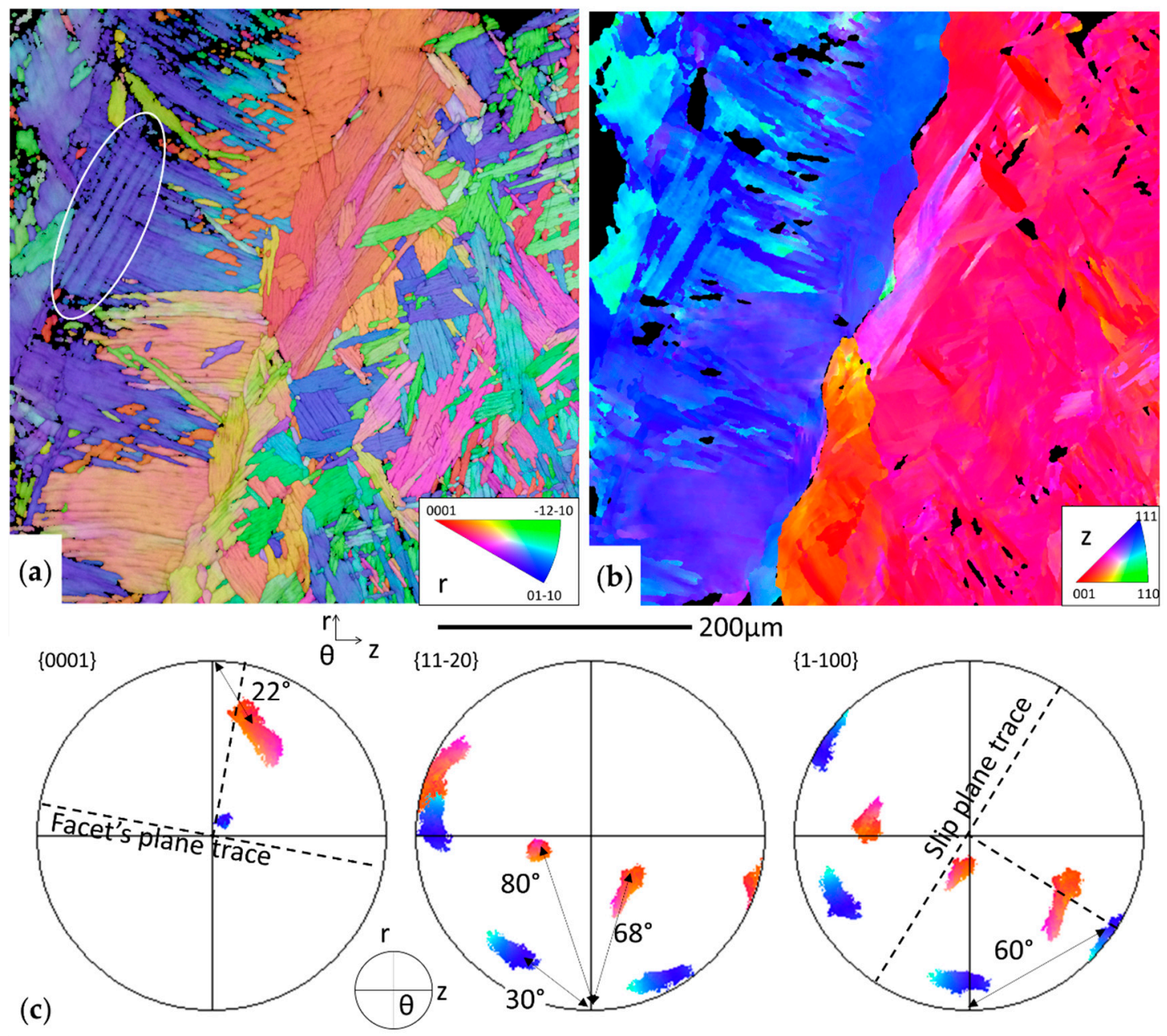

Figure 7. EBSD map over the section transverse to the facet seen in Figure $4 \mathrm{~b}$,c: (a) measured $\alpha$ IPF//z map; (b) Reconstructed $\beta$ IPF//z map; (c) $\alpha$ orientations plotted as PFs of two specific colonies, the red one below the facet and the blue one with deformation marks and additional dotted traces of facet and slip planes. 


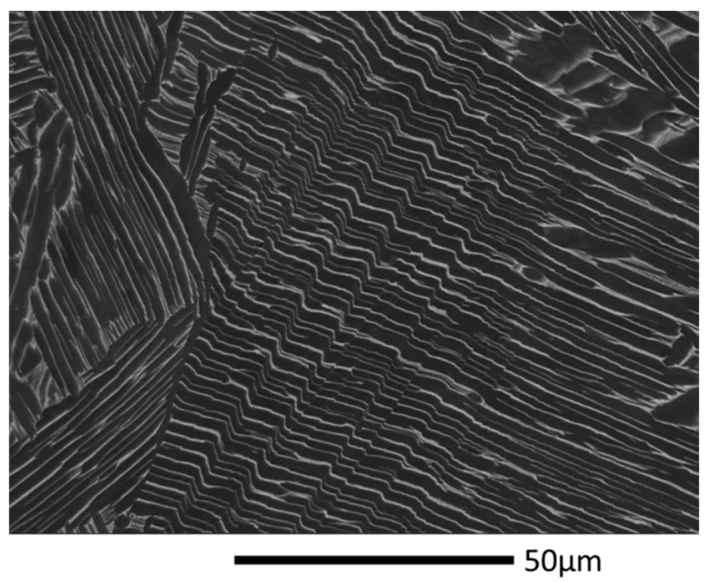

(a)

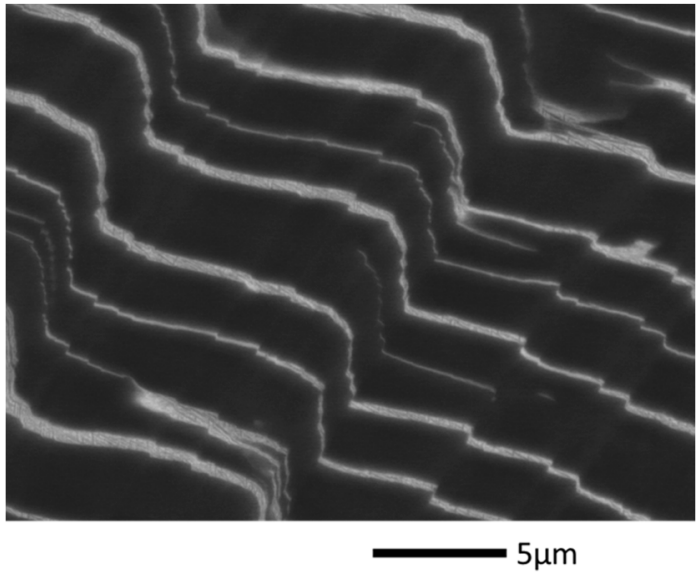

(b)

Figure 8. BSE images showing shearing at the $\alpha / \beta$ lamellae interfaces in the colony adjacent to the facet colored in blue Figure 7a: (a) low and (b) higher magnification.

The trace is consistent with the trace of a prismatic slip plane as seen Figure $7 \mathrm{c}$ (see the trace analysis on the $\{1-100\} \alpha \mathrm{PF})$. The corresponding slip system has a Schmid factor of $\cos \left(60^{\circ}\right) \cdot \cos \left(30^{\circ}\right)>0.4$ which is favorable for slip. The red colony below the facet has a Schmid factor of about $0.3-0.35$ for basal slip. However, no shearing at the $\alpha / \beta$ lath interface was observed neither in the $<111>/ / z$ oriented $\beta$ grain nor in the $<100>/ / z$ one. This may indicate that little plastic deformation took place before basal cleavage (notice that the facet plane is consistent with a basal plane as indicated Figure $7 \mathrm{~b}$ on the $\{0002\} P F$ by the dashed lines).

\section{Discussion}

\subsection{Influence of the Local Microstructure/Microtexture on Cold Dwell Failure in $\beta$-Forged Ti Alloys}

In our study, several cracks initiated subsurface with facets at the initiation site. The studied facet was $1.438 \mathrm{~mm}$ long and slightly inclined relative to the load (Figure 4). The underlying microstructure consisted of two Widmanstätten colonies decorating a prior $\beta$ grain boundary. EBSD revealed that the two colonies had their c-axis at $18-22^{\circ}$ to loading axis and were separated by a low-angle misorientation $\left(\sim 6^{\circ}\right)$. Adjacent to the initiation site was another large colony with slip bands shearing the $\alpha / \beta$ interfaces by prismatic slip for the $\alpha$ phase (Figure 7). In the $\beta$ phase, the slip traces analysis revealed that a $\{112\}<111>$ system was activated. Since both $\alpha$ and $\beta$ slip systems were parallel, the resistance to dislocation transfer between the $\alpha$ and $\beta$ interface was low [29].

The crystallography of dwell fracture surface has been less studied in lamellar microstructures [8,30-33] than in bimodal microstructures [1,34,35]. In 1979, Eylon et al. already had observed that facets could extend over several colonies [8]. The angles between habit planes made them thought that the c-axis was then common as also observed later by Pilchak et al. [30]. Those facets corresponded to the $10.5^{\circ}<0001>$ disoriented Burgers variants. To our knowledge, facets formed over two different $\beta$ grains have only been reported once by von Thüngen et al. [33] with the use of EBSD.

Mechanisms of formation of those facets are still under discussion. The inclination of the facets normal to the load axis is generally in the range $4-16^{\circ}$ [31] or around $45^{\circ}$ [32]. As noted by Evans, this difference is due to the modes controlling facet formation [36]. In this work, the mode is clearly the "quasi-cleavage" mode (renamed Low $\Delta \mathrm{K}[30]$ since 2009) where facets have a low inclination to the load. Different mechanisms may explain this type of fracture. The most popular is the Stroh model proposed by Bache et al. where stress redistribution between a "strong" and a "weak" grain trigger facet formation $[7,37]$. The "weak" grain act as dislocations source which pile up at the boundary of the "hard" grain inducing a shearing which ultimately lead to facet formation. The Stroh model provides a 
mechanism by which a facet may form in grains having low for Schmid factor for basal and prismatic slip (i.e., having their c-axis almost parallel to the load). However, this mechanism is mostly discussed for fractures encountered in bimodal microstructures. There, the facets from in primary $\alpha$ nodules with the c-axes lying in the range of $0-16^{\circ}$ to the load direction [34,36,38]. In our material, $9.3 \%$ vol of the $\alpha$ grains had their c-axis in the $0-15^{\circ}$ range from the load direction. So it is likely, such large colonies with these orientations were present in the sample. Since the fatal crack occurred at $\sim 20^{\circ}$, some other mechanism may have operated. This $20^{\circ}$ inclination is in agreement with the work of Bridier et al. [39]. Experimentally, Bridier et al. observed that cracks originate more often from grains having a Schmid factor larger than 0.24 on the basal slip system. In our work, the Schmid factor of the colonies underlying the facet was above this value but no basal slip activity has been observed. The Schmid factor approach does not account for all factors influencing facet formation, like stress redistribution due to elastic anisotropy [40] and grain neighborhood [41]. More complex approaches may account for the facet formation $[10,42]$.

The last factor which influence facet formation is the size of the crystallographic features (also called structural units [43]). Indeed, the larger the grains, the larger the dislocation source (for the "weak" grain) and the larger the resulting facet (in the "strong" grain). The size of structural units depends strongly on the thermomechanical history of the material and are discussed in the next section.

\subsection{Analysis of the Propension of the $\alpha$ Feather-Like Microstructures in Relation to the $\beta$ Forged Microtexture}

In our study, crack initiation was found to occur in large feather-like $\alpha$ structures. A first major result concerns the orientations of these colonies; they have their c-axis at $18-22^{\circ}$ to the loading axis (in the present dwell test: the radial direction of the disk). The $\alpha$ texture in the most deformed part of the disk is characterized by a main $<11-20>\alpha / / z$ fiber (Figure $2 \mathrm{a}$ ). This brings the c-axis into the radial directions of the disk.

A second major result shows that these feather-like $\alpha$ colonies with close crystallographic orientations have precipitated at prior $\beta$ GBs with the specific misorientations listed in Table 1. For example, in Figure 6 , the $\beta$ GB had a misorientation of $\sim 53^{\circ}$ around $<110>$. This misorientation is at $4.5^{\circ}$ from the $49.5^{\circ}<110>$ of special GB. Therefore, the closest variants common to both $\beta$ grains are at $4.5^{\circ}$ from each other and a LAGB remained at the localization of the prior $\beta$ GB. The presence of large clusters of colonies of similar orientation was already reported in the literature under different names: "double colonies" [20], "double Burgers boundary" [44], "feather microstructure" [45], or "plumes" $[15,46]$.

These feather-like $\alpha$ colonies develop from precursors of $\alpha$ GB layers that continuously decorate the $\beta$ GBs with the same unique orientation, i.e., minimizing the BOR deviation with both $\beta$ grains. This phenomenon is referred to as the double Burgers variant selection (or 2BOR-VS) in the following. The 2BOR-VS has been analyzed in details in different studies [20,47]. Shi et al. found that 2BOR-VS operates on $\beta$ GBs that deviate from the strict special misorientations up to a tolerance of $15^{\circ}$ [47]. Liu et al. measured that 2BOR-VS was always respected when the tolerance around special boundaries was lower than $10^{\circ}$. Beyond this tolerance, the fraction decreases linearly until $15^{\circ}$ where it reaches the random occurrence of variants. Liu et al. also that those variants nucleate earlier than other variants [20] giving them a growth advantage over other colonies. Indeed, since those variants maintain a near Burgers relationship with both grains they are energetically favored. As a consequence, the propensity to develop such a configuration depends strongly on the prior $\beta$ texture and microtexture and the inherited $\alpha$ transformation texture and microtexture, as further discussed in the following.

The occurrence of the special $\beta$ boundaries depends essentially on the texture and the microtexture of the $\beta$ grains. In itself, a $\beta$ texture can result in a very high proportion of special GB and therefore of double colonies, even if the $\beta$ grains are randomly arranged. In particular, in [48], it was shown that the texture resulting from uniaxial compression composed of $50 \%$ of a $<111>/ / z$ fiber with a $<100>/ / z$ fiber, has a very high potential for double colonies. This can of course be amplified by the local arrangement 
of $\beta$ grains, available on reconstructed maps and further referred to as the misorientation distribution function (MODF).

In the present work, the fraction of special GBs (at $10^{\circ}$ ) and the fraction giving rise to double colonies was measured from the $\beta / \alpha$ EBSD map of Figure 2 using DECRYPT. The results are presented in Figure 9. To evaluate the accuracy, the EBSD map of Figure 2 was divided into four maps, and the data from each sub-map was averaged and the error bars correspond to two standard deviations. The fraction of special GBs is represented by white bars over which the fraction decorated by double colonies is dashed (for comparative purpose, the black bars give the theoretical fraction of special GBs for the measured $\beta$ texture and a random MODF). Special GBs represent $46 \%$ of all boundaries. The majority of double colonies are formed at Type I boundaries. Type I boundaries are the most present because of the high fraction of LAGBs and a third of them give rise to double colonies. Type II and Type III GBs are less present but give rise very often to double colonies ( $>80 \%$ of the cases). Their cumulated contribution is therefore almost equivalent to Type I GBs. Meanwhile, the contribution of Type IV is almost negligible. These results are in agreement with the results of Liu et al. who also noticed that Type II and III GBs had the highest fraction of $\alpha$ GB respecting 2BOR-VS [20].

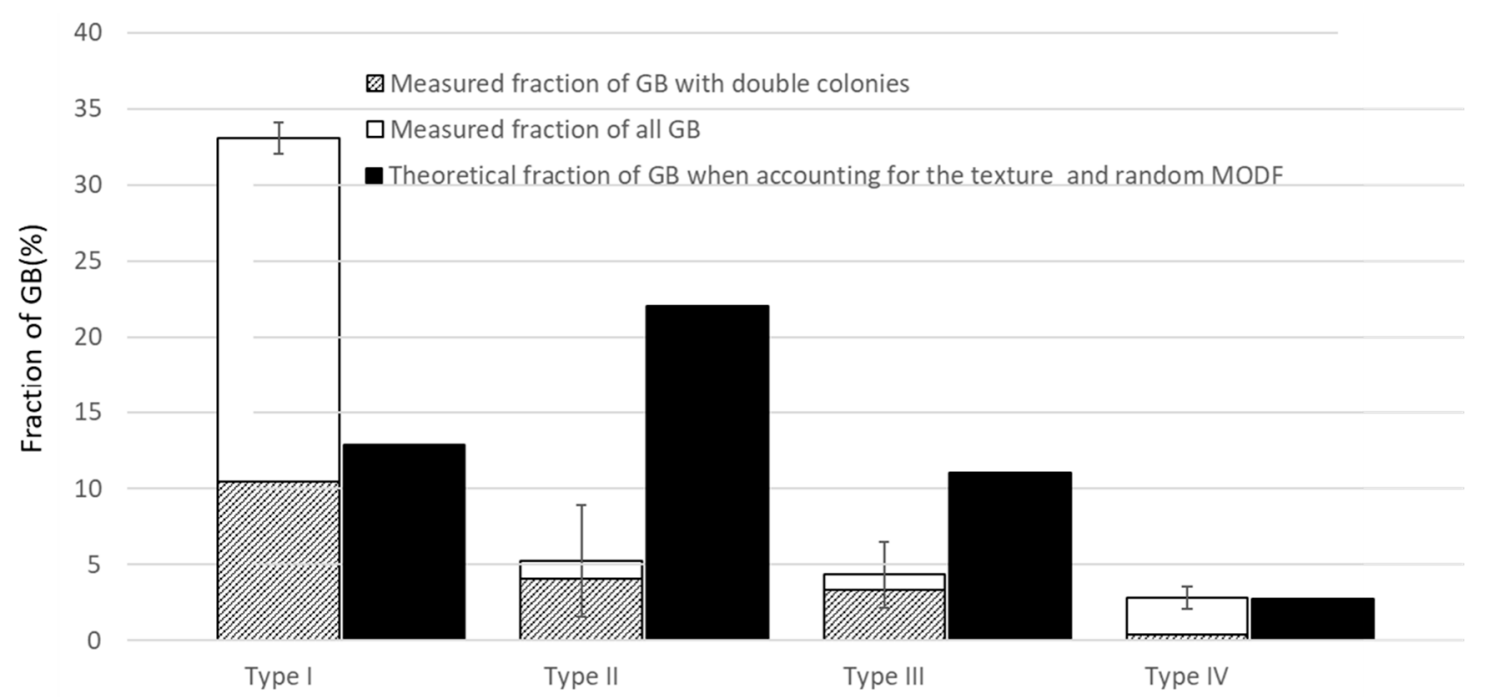

Figure 9. Fraction of special GB in the disk (from data of Figure 2) identified with a tolerance of $10^{\circ}$.

Comparing the experimental fraction of special $\beta$ GBs with the theoretical one (for the measured $\beta$ texture and a random MODF) shows that the Type I fraction is much higher than expected in a random MODF. This is because prior $\beta$ grain fragmentation occurs mostly through a recovery mechanism [25]. Inversely, Type II and III boundaries occurs less than in the random MODF.

The shape of the $\beta$ grains also has a significant contribution to the size of the feather-like colonies. The 3D shape of the $\beta$ grains is an oblate ellipsoid with an aspect ratio $a / c>10$. This morphology increases the interfacial area density of $\beta$ GB relative to an equiaxed microstructure (at equivalent grain volume). This interfacial area density increase linearly with the $\mathrm{a} / \mathrm{c}$ ratio. It increases even more when the grains have an prolate shape. However, with flat oblates, most boundaries are near-planar which may favor wetting and nucleation of Widmanstätten colonies. Indeed, in our microstructure, Widmanstätten colonies represent a volume fraction of $25 \%$.

A last parameter influencing double colonies is the cooling rate. At a high cooling rate, a displacive transformation takes place and 2BOR-VS seems to occur less often whereas when the transformation is diffusive a strong variant selection occurs [49].

Dwell fatigue properties could be better understood by taking into account the $\beta$ texture and microtexture induced by forging and subsequent recrystallization. First, the fraction of $<111>/ / z$ and $<100>/ / z$ components resulting from uniaxial compression of bcc metals vary with strain [50]. Then, recrystallization has been reported to lower texture intensities, drastically reducing the $<111>/ / z$ 
grains and slightly reducing the $<100>/ / z$ ones [24]. Moreover, recrystallization also leads to equiaxed grains, consequently lowering the interfacial area density. Both contribution may significantly decrease the number and the size of Widmanstätten colonies. In any case, the methodology described here for the analysis of the local texture in a forged disk offers new opportunities to optimize the material properties by a better control of the $\beta / \alpha$ local texture.

\section{Conclusions}

Dwell-fatigue crack initiation sites were analyzed from specimens taken from the most deformed part of a forged Ti6242 disk with a lamellar microstructure. Advanced EBSD analysis was applied to characterize the $\alpha$ and prior $\beta$ texture and microtexture of the forging as well as the crystallography of facetted crack initiation sites. The main findings are listed below:

1. Facetted cracks initiate in large feather-like $\alpha$ structures consisting of two Widmanstätten colonies decorating a prior $\beta$ grain boundary. They have close orientations with their c-axis at $18-22^{\circ}$ to the loading axis (in the present dwell test: the radial direction of the disk).

2. Adjacent to the initiation site, large colonies with evidence of slip bands are clearly seen. Thus, the facet formation seems triggered by stress redistribution from a "weak" to a "strong" region due to the elastic and plastic anisotropy of Titanium alloys.

3. The $\alpha$ texture in the most deformed part of the disk is characterized by a main $<11-20>\alpha / / z$ fiber ( $\mathrm{z}$ being the compression direction of the forging). This produces strong $\alpha$ regions with the $\mathrm{c}$-axis in the radial directions of the disk.

4. This texture is inherited from the prior $\beta$-forged texture: it is a sharp texture characterized by two fibers: $54 \%$ of $<100>/ / z$ and $26 \%$ of $<111>/ / z$.

5. The analysis of the $\beta$-reconstructed map shows that $45 \%$ of the $\beta$ grain boundaries are able to share close-oriented colonies to form a 'strong' feather like structure. Among them, most of the HAGBs and $30 \%$ of the LAGBs are effectively decorated by such unfavorable configurations for dwell fatigue properties.

Author Contributions: Data curation, L.G., Y.S., and N.G.; investigation, Y.S.; methodology, L.G. and N.G.; project administration, L.G., P.D., J.G., and N.G.; resources, P.D.; software, L.G.; supervision, L.G., J.G., and N.G.; validation, P.D.; writing-original draft, L.G. and N.G.; writing-review \& editing, L.G., P.D., and N.G. All authors have read and agreed to the published version of the manuscript.

Funding: This research received no external funding.

Conflicts of Interest: The authors declare no conflict of interest.

\section{References}

1. Bache, M.R.; Cope, M.; Davies, H.M.; Evans, W.J.; Harrison, G. Dwell sensitive fatigue in a near alpha titanium alloy at ambient temperature. Int. J. Fatigue 1997, 19, 83-88. [CrossRef]

2. Kassner, M.E.; Kosaka, Y.; Hall, J.S. Low-cycle dwell-time fatigue in Ti-6242. Metall. Mater. Trans. A 1999, 30, 2383-2389. [CrossRef]

3. Lefranc, P. Endommagement sous Chargement Cyclique avec Temps de Maintien de L'alliage de Titane Ti-6242: Rôle de L'hydrogène Interne. Ph.D. Thesis, Université de Poitiers, Poitiers, France, 2008.

4. Germain, L.; Gey, N.; Uta, E.; Humbert, M. EBSD Study of Local Texture Heterogeneities in Bimodal Titanium IMI834-From Their Formation during Manufacturing to Their Influence on Dwell Fatigue Behavior; University of Sheffield: Sheffield, UK, 2008.

5. Gey, N.; Bocher, P.; Uta, E.; Germain, L.; Humbert, M. Texture and microtexture variations in a near- $\alpha$ titanium forged disk of bimodal microstructure. Acta Mater. 2012, 60, 2647-2655. [CrossRef]

6. Joseph, S.; Bantounas, I.; Lindley, T.C.; Dye, D. Slip transfer and deformation structures resulting from the low cycle fatigue of near-alpha titanium alloy Ti-6242Si. Int. J. Plast. 2018, 100, 90-103. [CrossRef]

7. Bache, M. A review of dwell sensitive fatigue in titanium alloys: The role of microstructure, texture and operating conditions. Int. J. Fatigue 2003, 25, 1079-1087. [CrossRef] 
8. Eylon, D. Faceted fracture in beta annealed titanium alloys. Metall. Trans. A 1979, 10, 311-317. [CrossRef]

9. Hasija, V.; Ghosh, S.; Mills, M.J.; Joseph, D.S. Deformation and creep modeling in polycrystalline Ti-6Al alloys. Acta Mater. 2003, 51, 4533-4549. [CrossRef]

10. Dunne, F.P.E.; Rugg, D. On the mechanisms of fatigue facet nucleation in titanium alloys. Fatigue Fract. Eng. Mater. Struct. 2008, 31, 949-958. [CrossRef]

11. Briffod, F.; Bleuset, A.; Shiraiwa, T.; Enoki, M. Effect of crystallographic orientation and geometrical compatibility on fatigue crack initiation and propagation in rolled Ti-6Al-4V alloy. Acta Mater. 2019, 177, 56-67. [CrossRef]

12. Shen, W.; Soboyejo, W.O.; Soboyejo, A.B.O. An investigation on fatigue and dwell-fatigue crack growth in Ti-6Al-2Sn-4Zr-2Mo-0.1Si. Mech. Mater. 2004, 36, 117-140. [CrossRef]

13. McBagonluri, F.; Akpan, E.; Mercer, C.; Shen, W.; Soboyejo, W.O. An investigation of the effects of microstructure on dwell fatigue crack growth in Ti-6242. Mater. Sci. Eng. A 2005, 405, 111-134. [CrossRef]

14. Lefranc, P.; Doquet, V.; Gerland, M.; Sarrazin-Baudoux, C. Nucleation of cracks from shear-induced cavities in an $\alpha / \beta$ titanium alloy in fatigue, room-temperature creep and dwell-fatigue. Acta Mater. 2008, 56, 4450-4457. [CrossRef]

15. Freiherr von Thungen, I. Effet Dwell: Relation Microstructure-Microtexture-Propriétés Mécaniques de L'alliage de Titane Ti6242. Ph.D. Thesis, ISAE-ENSMA Ecole Nationale Supérieure de Mécanique et d'Aérotechique, Poitiers, France, 2016.

16. Germain, L.; Gey, N.; Mercier, R.; Blaineau, P.; Humbert, M. An advanced approach to reconstructing parent orientation maps in the case of approximate orientation relations: Application to steels. Acta Mater. 2012, 60, 4551-4562. [CrossRef]

17. Germain, L. Merengue2 Software. Available online: http://lionelgermain.free.fr/merengue2.htm (accessed on 8 December 2014).

18. Burgers, W.G. On the process of transition of the cubic-body-centered modification into the hexagonal-close-packed modification of zirconium. Physica 1934, 1, 561-586. [CrossRef]

19. Germain, L.; Gey, N.; Humbert, M. Reconstruction of deformed parent grains from microstructure inherited by phase transformations. Scr. Mater. 2019, 158, 91-94. [CrossRef]

20. Liu, T.; Germain, L.; Teixeira, J.; Aeby-Gautier, E.; Gey, N. Hierarchical criteria to promote fast and selective $\alpha \mathrm{GB}$ precipitation at $\beta$ grain boundaries in $\beta$-metastable Ti-alloys. Acta Mater. 2017, 141, 97-108. [CrossRef]

21. Schmid, E.; Boas, W. Plasticity of Crystals, with Special Reference to Metals: With Special Reference to Metals; Springer: New York, NY, USA, 1968; ISBN 978-1-5041-1927-6.

22. Delfosse, J. Forgeage $\beta$ du Ti17: Propriétés en Fatigue. Ph.D. Thesis, Ecole centrale de Paris, Châtenay-Malabry, France, 2005.

23. Corre, S.L.; Forestier, R.; Brisset, F.; Mathon, M.-H.; Solas, D. Influence of $\beta$-Forging on Texture Development in Ti 6246 Alloy. In Proceedings of the 13th World Conference on Titanium; John Wiley \& Sons, Ltd.: Hoboken, NJ, USA, 2016; pp. 757-764. ISBN 978-1-119-29612-6.

24. Chaussy, F.; Driver, J.H. Evolutions microstructurales en compression uniaxiale à chaud de l'alliage $\beta$-Cez. Rev. Métall. 1996, 93, 1057-1066. [CrossRef]

25. Poletti, C.; Germain, L.; Warchomicka, F.; Dikovits, M.; Mitsche, S. Unified description of the softening behavior of beta-metastable and alpha+beta titanium alloys during hot deformation. Mater. Sci. Eng. A 2016, 651, 280-290. [CrossRef]

26. Wright, S.I.; Nowell, M.M.; Field, D.P. A Review of Strain Analysis Using Electron Backscatter Diffraction. Microsc. Microanal. 2011, 17, 316-329. [CrossRef]

27. Raabe, D.; Roters, F.; Marx, V. Experimental Investigation and Numerical Simulation of the Correlation of Recovery and Texture in Bcc Metals and Alloys. Textures Microstruct. 1996, 26-27, 611-635. [CrossRef]

28. Eylon, D.; Hall, J.A. Fatigue behavior of beta processed titanium alloy IMI 685. Metall. Trans. A 1977, 8, 981-990. [CrossRef]

29. Suri, S.; Viswanathan, G.B.; Neeraj, T.; Hou, D.-H.; Mills, M.J. Room temperature deformation and mechanisms of slip transmission in oriented single-colony crystals of an $\alpha / \beta$ titanium alloy. Acta Mater. 1999, 47, 1019-1034. [CrossRef]

30. Pilchak, A.L.; Bhattacharjee, A.; Rosenberger, A.H.; Williams, J.C. Low $\Delta \mathrm{K}$ faceted crack growth in titanium alloys. Int. J. Fatigue 2009, 31, 989-994. [CrossRef] 
31. Davidson, D.L.; Eylon, D. Titanium alloy fatigue fracture facet investigation by selected area electron channeling. Metall. Trans. A 1980, 11, 837-843. [CrossRef]

32. Ruppen, J.A.; Eylon, D.; McEviily, A.J. Subsurface Fatigue Crack Initiation of Beta-Annealed Ti-6AI-4V. Metall. Trans. A 1980, 11, 1072-1075. [CrossRef]

33. Freiherr von Thüngen, I.; Delaleau, P.; Villechaise, P. Dwell Fatigue of a Fully Lamellar Ti6242 Alloy: Deformation Mechanisms at Different Scales. In Proceedings of the 13th World Conference on Titanium; John Wiley \& Sons, Ltd.: Hoboken, NJ, USA, 2016; pp. 949-954.

34. Sinha, V.; Mills, M.J.; Williams, J.C.; Spowart, J.E. Observations on the faceted initiation site in the dwell-fatigue tested ti-6242 alloy: Crystallographic orientation and size effects. Metall. Mater. Trans. A 2006, 37, 1507-1518. [CrossRef]

35. Uta, E.; Gey, N.; Bocher, P.; Humbert, M.; Gilgert, J. Texture heterogeneities in $\alpha \mathrm{p} / \alpha$ s titanium forging analysed by EBSD-Relation to fatigue crack propagation. J. Microsc. 2009, 233, 451-459. [CrossRef]

36. Evans, W.J. The influence of microstructure on dwell sensitive fatigue in a near alpha titanium alloy. Scr. Metall. 1987, 21, 469-474. [CrossRef]

37. Stroh, A.N. The formation of cracks as a result of plastic flow. Proc. R. Soc. Lond. Ser. Math. Phys. Sci. 1954, 223, 404-414. [CrossRef]

38. Evans, W.J.; Bache, M.R. Dwell-sensitive fatigue under biaxial loads in the near-alpha titanium alloy IMI685. Int. J. Fatigue 1994, 16, 443-452. [CrossRef]

39. Bridier, F.; Villechaise, P.; Mendez, J. Slip and fatigue crack formation processes in an $\alpha / \beta$ titanium alloy in relation to crystallographic texture on different scales. Acta Mater. 2008, 56, 3951-3962. [CrossRef]

40. Lhadi, S.; Berbenni, S.; Gey, N.; Richeton, T.; Germain, L. Micromechanical modeling of the effect of elastic and plastic anisotropies on the mechanical behavior of $\beta$-Ti alloys. Int. J. Plast. 2018, 109, 88-107. [CrossRef]

41. Pourian, M.H.; Bridier, F.; Pilvin, P.; Bocher, P. Prediction of crack initiation sites in alpha Ti-alloys microstructures under dwell-fatigue using Cellular Automaton simulation method. Int. J. Fatigue 2016, 85, 85-97. [CrossRef]

42. Ozturk, D.; Pilchak, A.L.; Ghosh, S. Experimentally validated dwell and cyclic fatigue crack nucleation model for $\alpha$-titanium alloys. Scr. Mater. 2017, 127, 15-18. [CrossRef]

43. Germain, L.; Bache, M.R. Crystallographic Texture and the Definition of Effective Structural Unit Size in Titanium Products. In Ti-2007 Science and Technology, Proceedings of the 11th World Conference on Titanium, Kyoto, Japan, 3-7 June 2007; Ninomi, M., Akiyama, S., Ikeda, M., Hagiwara, M., Maruyama, K., Eds.; Japan Institute of Metals: Kyoto, Japan, 2007; Volume I, pp. 953-956.

44. Farabi, E.; Hodgson, P.D.; Rohrer, G.S.; Beladi, H. Five-parameter intervariant boundary characterization of martensite in commercially pure titanium. Acta Mater. 2018, 154, 147-160. [CrossRef]

45. Sasaki, L.; Hénaff, G.; Arzaghi, M.; Villechaise, P.; Delfosse, J. Effect of long term aging on the fatigue crack propagation in the $\beta$ titanium alloy Ti 17. Mater. Sci. Eng. A 2017, 707, 253-258. [CrossRef]

46. Kuzmenkov, K. Study of Dwell-Effect on Behaviour and Fracture of the Alloy Ti-6242. Ph.D. Thesis, École Nationale Supérieure des Mines de Paris, Paris, France, 2012.

47. Shi, R.; Dixit, V.; Fraser, H.L.; Wang, Y. Variant selection of grain boundary $\alpha$ by special prior $\beta$ grain boundaries in titanium alloys. Acta Mater. 2014, 75, 156-166. [CrossRef]

48. Liu, T.; Germain, L.; Teixeira, J.; Aeby-Gautier, E.; Gey, N. Criteria for fast and selective $\alpha$ precipitation at $\beta$ grain boundaries in Ti-alloys-Consequence for in-service microstructures. In Proceedings of the 14th World Conference on Titanium, Nantes, France, 10-14 June 2019.

49. Beladi, H.; Chao, Q.; Rohrer, G.S. Variant selection and intervariant crystallographic planes distribution in martensite in a Ti-6Al-4V alloy. Acta Mater. 2014, 80, 478-489. [CrossRef]

50. Primig, S.; Leitner, H.; Knabl, W.; Lorich, A.; Clemens, H.; Stickler, R. Textural Evolution during Dynamic Recovery and Static Recrystallization of Molybdenum. Metall. Mater. Trans. A 2012, 43, 4794-4805. [CrossRef]

(C) 2020 by the authors. Licensee MDPI, Basel, Switzerland. This article is an open access article distributed under the terms and conditions of the Creative Commons Attribution (CC BY) license (http://creativecommons.org/licenses/by/4.0/). 